\title{
О. В. Бочкарева https://orcid.org/0000-0003-3616-8545
}

\section{Музыкальный дискурс в условиях современного медиапространства}

Для цитирования: Бочкарева О. В. Музыкальный дискурс в условиях современного медиапространства // Ярославский педагогический вестник. 2021. № 1 (118). С. 170-177. DOI 10.20323/1813-145X-2021-1-118-170-177

Музыкальная культура играет важную роль в становлении и развитии личности и мыслится как пространство диалога, пространство духовности. Формируемый в СМИ медиаобраз реальной действительности возникает на основе коллективно вырабатываемого смыслового поля представляемой информации, фиксирующего ценности воспринимающей аудитории в процессе их актуализации. Механизм функционирования ценностного медиапространства организуется значимыми персонами с их пониманием культурной, политической, общественной ситуации, которое признает большинство аудитории, индивидуальное видение лидера (реального или мнимого) возводится в ранг духа времени. Подобие реальности, симулякр, рождается тогда, когда в сознании потребителя реальное событие по масштабам несопоставимо с тем, как оно представлено в СМИ: сложные жизненные проблемы упрощаются, обрастая мнимым ценностным контекстом, а неразрешимость противоречий снимается, предлагается в виде готового ответа в доступной упаковке, тем самым реальная действительность мифологизируется. Важное место в медиапростанстве занимает современный музыкальный дискурс, выполняющий информационную и оценочную функции на основе использования определенных языковых средств в музыкальной рецензии, обзоре, эссе, очерках, творческих портретах музыкантов, арт-хрониках, репортажах, музыкальных передачах, документальных аудио- и видеофильмах и др. Музыкальный дискурс в современном медиапространстве представлен в трех категориях: профессиональной, профанной и смешанной. Происходящие в современном медиапространстве явления, такие как рост фан-культуры, обилие блогов, блогеров и др., свидетельствуют о преобладании непрофессионального контента над профессиональным, расширение которого требует решения новых этикофилософских, образовательных и воспитательных проблем. Музыкальные передачи, транслируемые каналом «Культура» («Абсолютный слух» (ведущий - Геннадий Янин), «Нескучная классика» (ведущая - Сати Спивакова) и др.), восстанавливают общественную значимость искусства на основе уважительного отношения к творцам и их творчеству, возрождают просветительские принципы отечественной музыкально-критической журналистики, выполняют важную функцию «служения музыке».

Ключевые слова: музыкальный дискурс, музыкальная культура, медиапространство, блогер, фанат, массовое музыкальное искусство, телевизионная музыкальная передача.

\section{O. V. Bochkareva}

\section{Musical discourse in the conditions of modern media space}

Musical culture plays an important role in the formation and development of the individual and is conceived as a space of dialogue, a space of spirituality. The media image of real reality formed in the media arises on the basis of the collectively developed semantic field of the presented information, which fixes the values of the perceiving audience in the process of their actualization. The mechanism of valuable media space functioning is available to relevant persons with their understanding of the cultural, political, social situation that recognizes the majority of the audience, individual vision of the leader (real or imaginary) elevated to the rank of Zeitgeist. The semblance of reality, a simulacrum is born when a real event in the consumer's mind is not comparable in scale to how it is presented in the media: complex life problems are simplified, overgrown with an imaginary value context, and the insolubility of contradictions is removed, offered in the form of a ready-made answer in an accessible package, thereby real reality is mythologized. An important place in the media space is occupied by modern musical discourse, which performs an informational and evaluative function based on the use of certain language means in music reviews, digests, essays, creative portraits of musicians, art chronicles, reports, music programs, documentary audio and video films, etc. Musical discourse in the modern media space is presented in three categories: professional, profane and mixed. The phenomena occurring in the modern media space, such as the growth of fan culture, the abundance of blogs, bloggers, etc., indicate the predominance of non-professional content over professional, the expansion of which requires solving new ethical, philosophical, educational and upbringing problems. Music programs broadcast by the Kultura channel: «Absolute Hearing» (presenter - Gennady Yanin, «Not dull Classics» (presenter - Sati Spivakova) etc., restore the

(C) Бочкарева О. В., 2021 
social significance of art on the basis of respect for the creators and their work, revive the educational principles of domestic music-critical journalism, perform an important function of «service to music».

Keywords: musical discourse, musical culture, media space, blogger, fan, mass musical art, television music program.

\section{Введение}

В современную эпоху, когда человек все более и более общается дистанционно, когда большую часть времени он проводит в Интернете, начинает постепенно стираться грань между реальным и представляемым, между действительностью и ее образом. Исследователи современного медиапространства и существования музыкальной культуры в нем [Арпентьева, 2019; Курышева, 2007; Миронов, 2006; Шапинская, 2019; Barnier, 2008; Burnett, 2008; Machin, 2010] и др. отмечают, что coвременный человек находится как бы в двух реальностях: одной, реально ощущаемой, в которой он живет, работает, и другой, виртуальной, представляемой, являющейся продуктом дискурса, интерпретации, репрезентации.

\section{Актуальность исследования}

В настоящее время своеобразным образом переплетаются реальное и виртуальное пространства действительности. Ученые выделяют такую характерную черту современного медиапространства, как иллюзорность, когда стирается грань между восприятием реальности и ее имиджем, происходит «замещение непосредственного переживания нагромождением представлений» [Зубанова, 2008, с. 7]. Современная эпоха по-разному оценивается авторами: как «общество спектакля» (Ш. Дебор), царство чистой видимости (подобно Платоновскому царству теней), бесконечная симуляция (присутствие в СМИ «безответной речи», лишь симулирующий ответ) и др.

Медийные агенты (журналисты, редакторы, режиссеры) носят свои «журналистские очки», благодаря которым видят одно и не замечают другого. Присутствие избирательности оказывает влияние на решения: кто попадет в эфир, в какое время попадет, а кто останется за порогом. Интернет предлагает пользователям «подсказки»: что посмотреть? (мы подобрали видеосюжеты, которые будут Вам интересны), что почитать? (мы подобрали для Вас интересную информацию) и т. д. Человек, обыватель, не имея своего мнения и запросов, подобен флюгеру, который умело направляется СМИ и Интернетом. Успех влияния порой определяет не реальность, правда, а мир мнений, который репрезентируют агенты влияния. Для потребителя очевидной («видной для очей») является ситуация узнавания, когда сообщаемая информация вероятностно правдиво поданная, ока- зывается очередным фейком. Поле задаваемых смыслов опирается на набор сформированных представлений обывателя, резонирующих с социальными архетипами. Корреспондент (диктор, ведущий) обыгрывает доступность информации для публичного восприятия, конструируя общность коллективных представлений, общность позиций по определенному вопросу, формируя информационное поле, в котором рождается чувство солидарности аудитории. Довольно часто в процессе ведения дискуссии сложные проблемы упрощаются, неразрешимость противоречий подается как готовый ответ в доступной трактовке и упаковке, тем самым реальная действительность мифологизируется, обрастая порой мнимым ценностным контекстом. Так рождается симулякр, подобие, видимость, инверсия реальности, когда в сознании потребителя реальное событие по масштабам отнюдь не сопоставимо с тем, как оно представлено в СМИ.

\section{Постановка проблемы исследования}

Обрастая символическими формами, медиапространство образует всевозможные связи между текстами и образами, воспринимаемыми людьми в качестве своего рода смысловых конструктов, на основе которых происходит объяснение реальных событий. Достаточно часто можно наблюдать картину, когда корреспонденты СМИ не просто сообщают о происходящем событии, а придают особую значимость происходящему, утрируя отдельные факты и замалчивая о других. Высвечивание особых, с точки зрения корреспондента, событий переводит малоценное содержание в статус особо важного, приоритетного. Привнесение доминирующего смысла в сообщаемую информацию, интенсификация количественнокачественных проблемных зон в обсуждении повышает общественный статус и значимость для потребителя, таким образом реально малозначимая информация приобретает референтный смысл. Так, постепенно ценностноинформационное поле медиасферы на основе трансляции мнений, ситуативных обзоров, расстановки акцентов в информационных сообщениях становится основой ценностной картины мира потребителя. Возникает своего рода зеркальный диалог «Я»- «Другой», где в качестве зеркала выступают медийные средства. 
Особый интерес в объяснении механизмов влияния СМИ представляет персонификация ценностного поля на основе его одушевления - приглашение в студию особо значимых персон, личностей, которые известны, значимы для общественной аудитории. Мнение, высказываемое референтным для публики человеком, выполняет роль катализатора дискуссии, порождает новые смыслы в сообщаемой информации, концентрирует мнение лидера; обнажая противоречия, побуждает к оппонированию. Основная задача лидеров мнений в дискуссии как экспертов по тому или иному вопросу заключается в том, чтобы перевести непонятную для обывателя информацию в понятную, трудный материал сделать доступным для понимания, опираясь на круг привычных представлений большинства зрителей, сидящих у экрана. Такое «заземление» информации получило название «анкоринг» (сведение трудного к простому, упрощение, опора на круг привычных образов). Большинство приглашенных в студию известных ученых, политиков, артистов (professional celebrities) действительно являются лидерами мнений в силу своих реальных достижений в профессии, но иногда популярность персоны во многом обуславливается частотой «мелькания» на экране, появления в эфире и определяется не реальными достижениями, не «способностью быть», а «способностью быть замеченным» (П. Бурдье), тогда возникает эффект «мнимого ареола». Ценностные установки значимой персоны на основе механизма проекции возводятся в ранг всеобщности, а высказывания приобретают характер разъяснения с предельной конкретизацией. Так работает механизм функционирования ценностного медиапространства, организованный значимыми персонами, с их пониманием культурной, политической, общественной ситуации, которое принимается, признается большинством людей, индивидуальное видение лидера возводится в ранг духа времени.

\section{Методы исследования}

Особую нишу в современном медиапространстве занимает музыкальный дискурс.

В эпоху медийности, когда Интернет «оттягивает» на себя большую часть времени современного человека, смещается баланс существования музыкальной культуры в сторону все большего заполнения достаточно примитивными «образцами» шоу-индустрии.

«Ухо» современной молодежи настроено на звучание, транслируемое с записывающих устройств, телефонов и гаджетов; фактически ограничивается общение с живым звуком, интер- нет-сайты пестрят заказами на модный товар массовой культуры. Медики бьют тревогу по поводу ухудшения слуха (значительно чаще молодые люди стали приобретать слуховые аппараты) и зрения (увеличения на 30 процентов случаев близорукости с появлением смартфонов). Компьютерные игры с агрессивным поведенческим сюжетом, стирающие грань между реальным и виртуальным, ослабление живых контактов между сверстниками, виртуальная беспризорность детей, отсутствие внимания со стороны занятых добыванием денег родителей, сквернословие, наркомания, буллинг и т. д. оказывают негативное влияние и на психическое здоровье молодежи. Действие музыки сравнивается с действием «тяжелого синтетического наркотика», «музыка приводит в состояние кайфа» (из высказываний студентов при ответе на вопрос анкеты: «Как на Вас влияет музыка?»), а школьники на этот вопрос отвечали, что «музыка позволяет забыться, отвлечься от существующих проблем», «с музыкой легко отдыхать вместе», «музыка - мир грез». Поставленная на коммерческие рельсы эстрадная музыка (popmusic), по данным социологических исследований, занимает первое место в рейтинге предпочтений аудитории в возрасте от 18 до 21 года, треть опрошенных респондентов считают возможным использование ненормативной лексики в текстах песен или в качестве обозначения впечатления, ответной реакции на звучание прослушанной музыки, причем количество девушек, допускающих грубые ругательства, в два раза превышает количество юношей [Борисова, 2012].

Широкое распространение в медиапространстве получил блог, в том числе и музыкальный, как коммерческая и дискуссионная площадка, позволяющая в определенной мере индивидуализировать онлайн-общение. Легкий, непринужденный тон беседы, допускающий отход от темы обсуждения, регулярность апдейта, высокая значимость ссылок на другие сайты, возможность участия или достоверная имитация участия в дискуссии делают музыкальный блог достаточно популярным у потребителей контента. Анализ типов высказываний в музыкальных блогах, которые используются при обсуждении тех или иных тем, позволил выявить определенные типы сообщений:

- полемические высказывания, когда фанат выражает недовольство официальными медиаканалами и ресурсами;

- позитивные высказывания, связанные с реальными практическими предложениями об ор- 
ганизации музыкальных выступлений, концертов рок- и поп-звезд;

- высказывания, связанные с рекламированием любимой группы или исполнителя или критикой услышанного клипа, хита и т. д.;

- эмоциональные суждения о прослушанной музыке или исполнителе, не несущие никакого информационного сообщения.

Блогер, организующий музыкальный чат, часто выполняет роль «своего парня», понимающего и принимающего в свой круг общения, говорящего на-равных, не допускающего морализаторства по отношению к собеседнику. В блогах не установлены ни этические, ни культурные нормы, поэтому возможность использования ненормативной лексики становится «нормой». В определенной степени «общение» в блоге можно назвать симулякром, так как всякий, кто в нем участвует, считает себя сопричастным к art-процессу. Блогер, имеющий музыкальные предпочтения, часто оказывается фанатом той или иной музыкальной рокгруппы, тратит много времени на продвижение ее продукта, объединяя вокруг себя таких же ее почитателей. Фаны стараются размещать полюбившиеся образцы рок-музыки на новостных сайтах, в архивах, других блогах, часто обновляют информацию о любимых певцах и группах, занимаются популяризацией их концертов, тематических музыкальных собраний, вечеринок. Рост фанкультуры свидетельствует, что «непрофессиональный контент вытесняет из медиаполя определенную часть профессионально созданного, и это ставит новые этико-философские вопросы в долгосрочной перспективе развития профессиональных массмедиа, музыки, кино и др.» [Гольденцвайг, 2009, с. 73].

Исследователи музыкальной массовой культуры отмечают тенденцию ослабления хитфеномена в современное время и связывают это с появлением новых безграничных возможностей выбора, отражающего разнохарактерные запросы интернет-аудитории, а в качестве главной причины выдвигают ослабление связей влияния организаций метаиндустрии, создающих и репродуцирующих хиты. Поэтому все активнее в качестве известных инструментов удержателей аудитории в разнообразных музыкальных клипах, как коммерческих продуктах, используются уложенные в красивую обертку сексуальность, насилие и другие табуированные темы. К. Э. Разлогов отмечает, что «массмедиа повсеместно распространяют одни и те же мелодии, одни и те же иерархии звезд и героев, одни и те же представления о том, что та- кое хорошо и что такое плохо» [Разлогов, 2019, c. 150$]$.

Важное место в медиапространстве занимает современный музыкальный дискурс, который, выполняя информационную и оценочную функции, фиксирует использование определенных языковых средств в музыкальной рецензии, обзоре, эссе, очерках, творческих портретах музыкантов, арт-хрониках, репортажах, музыкальных передачах, документальных аудио- и видеофильмах и др. В настоящее время возникает потребность в подготовке музыкантов-журналистов, так как эту работу осуществляют либо профессиональные музыканты, не имеющие опыта работы в журналистике, либо журналисты, не имеющие профессионального музыкального образования. Работа музыканта-журналиста в СМИ, помимо профессиональной музыкальной подготовки, требует освоения комплекса знаний и умений в области журналистики: это и редакторская практика, и первичные умения сценариста, звукоооператора, видеомонтажа и др., которые позволяют авторам воплощать творческие проекты [Птушко, 2009].

\section{Результаты и дискуссии}

Музыкальный дискурс в отношении использования лексики представлен в трех категориях: профессиональной, профанной и смешанной.

Профессиональная лексика включает узкоспециальные музыкальные термины (в основном итальянского происхождения), понятные достаточно узкому кругу музыкантов; как правило, им присуща однозначность, эмоциональная и стилистическая нейтральность. Профессиональный дискурс с его обилием музыкальной терминологии значительно сужает количество обращений к тексту.

Профаннылй дискурс отличается стилистически сниженным уровнем текста с использованием жаргонизмов, сленга и даже обсценной лексики, часто используется в чатах, в блогах, в социальных сетях.

Смешанный тип дискурса базируется на объединении (смешении) упомянутых выше профессиональном и профанном дискурсах, адаптирует рассматриваемый материал для публики, во многом упрощая профессиональный дискурс, наполняет Интернет полупрофессиональными псевдотекстами о музыке.

Обращенность текстов к слушателям рокмузыки, поп-музыки предполагает минимальное использование музыкальной терминологии и чрезмерное употребление элативных эпитетов, так как цель данной продукции - завлечь аудиторию или разрекламировать новый «музыкальный то- 
вар». Употребление в таких текстах отдельных специфических музыкальных терминов, заимствованных из джаза, возможно, так как они находятся на слуху у публики, например, «12-тактовый блюз», «ритм-секция», «кавер-версия» (от англ. cover - 'покрывать'), обозначает музыкальную композицию, которая была ранее известна в исполнении другого музыканта и др. В отдельных текстах при анализе рок-музыки можно найти отдельные музыкальные термины, привлечение которых связано в основном с желанием обозначить статус и престижность, но в целом загруженность текста музыкальной терминологией не является характерной [Морозова, 2016].

Музыкальные передачи, транслируемые каналом «Культура» («Абсолютный слух» (ведущий Геннадий Янин, «Нескучная классика» (ведущая Сати Спивакова) и др.), восстанавливают общественную значимость искусства на основе уважительного отношения к творцам и их творчеству; возрождая просветительские принципы отечественной музыкально-критической журналистики, они выполняют важную функцию «служения музыке». Выразительное слово о музыке призвано вызывать интерес к музыкальному произведению, явлению, событию, представлять его в контексте исторической художественной традиции с современностью, ускорять процесс познания искусства и пробудить в себе творца. Восприятие искусства, связанное с вариативностью личностных ассоциаций, необходимо умело направлять, проясняя намерения автора, программу музыкального сочинения, уточняя музыкальное содержание.

Передача «Абсолютный слух» выстраивается по принципу объединения разнообразных тематических видеосюжетов или моносюжетов, сопровождающихся музыкой и представляющих сравнительно небольшие увлекательные экскурсы в историю искусства, историю музыки. Музыкальная заставка выполняет роль эмблемы, а слоган «Найти неизвестное в известном...» в единстве с укрупнением визуального плана ведущего отражает главный принцип передачи, направленность на захват внимания аудитории. Артистические умения, искусство риторики, знание законов психологии восприятия искусства, музыки позволяют ведущему передачи Г. Янину быть созвучным современному слушателю и зрителю, когда он рассказывает об интересных фактах из жизни и творчества великих композиторов прошлого на основе привлечения широкого объема средств театра, кино, балетного и изобразительного искусства, путешествуя по концертным залам всего мира и мемориальным музеям. Обращаясь к разным видам искусства, авторы передачи и ее ведущий подчеркивают идею о том, что художник, создавая, интерпретируя произведение, в образе воплощает свое «Я» как часть «Мы», тем самым объективирует свой субъективный мир. Таким образом, диалектика субъективно-объективной сопряженности присутствует во всех видах существования искусства: и в творчестве, и в сотворчестве исполнителя, зрителя, слушателя.

Передача «Нескучная классика» (ведущая Сати Спивакова) выстраивается в прямом эфире несколько иначе: в студию приглашаются известные музыканты, композиторы и исполнители, критики (А. Варгафтик), ученые, занимающиеся проблемами психологии музыкального восприятия (Д. Кирнарская), проблемами влияния музыки на мозг человека (Т. Черниговская) и др. В непринужденной беседе, которую мастерски выстаивает Сати Спивакова, обсуждается определенная проблема, каждому гостю предоставляется возможность высказаться, а музыкантам-исполнителям и выступить с концертным номером. Ведущая Сати Спивакова выступает в роли модератора, музыканта-лектора и музыканта-критика, так как, воплощая словесную композицию о музыке, не только передает информацию о музыкальном явлении или его идее, но и экспрессией слова, использованием метафор и живописных ассоциаций стремится вызвать интерес к обсуждаемой проблеме и настроить на ответный диалог гостей студии. Воплощение сценария со своей завязкой, кульминацией и развязкой, несущих эмоциональную и смысловую драматургию определенной обсуждаемой художественной идеи, сопровождается использованием риторических приемов, изменением темпа и ритма речи. Разбудить творческое воображение, настроить на образное восприятие музыкального произведения, вызвать эмоциональный отклик - непростые задачи, которые приходится решать модератору передачи, ее ведущей. Музыкальное произведение предрешает силу, глубину, насыщенность эмоциональной реакции участников телепрограммы и одновременно стимулирует индивидуально-личностное отношение и самораскрытие тех слушателей, которые находятся по другую сторону телевизионного экрана. В. В. Медушевский отмечает, что музыкальное произведение может выступать средством духовной связи, «обмена различными "мнениями" о жизни, точками зрения на нее, рожденными творческой фантазией композиторов...» [Медушевский, 1993, с. 118].

Исходящая из непосредственных эмоциональных переживаний оценка произведения определя- 
ет искренность эстетических суждений. Рассматриваемое как вербализованная форма бытия эстетического вкуса эстетическое суждение вторично по отношению к эмоциональной форме и связано с возможностью логической способности сознания проникать в содержание художественного образа. И. Кант замечал, что эстетические суждения - «синтетические суждения, так как они выходят за пределы понятия и даже созерцания объекта и присоединяют к нему ... чувство удовольствия〉 [Кант, 1963, с. 62].

Обмен суждениями о музыке в студии, помимо эмоциональной рефлексии, выполняет главную роль - гармонизирует музыкально-эстетический опыт личности, выявляя в нем главный критерий - красоту. И. Кант связывает эстетический вкус со «способностью судить о красоте». Диалогическая природа телепередачи «Нескучная классика» позволяет всем ее участникам и примкнувшим к ним зрителям развивать творческую способность музыкального вкуса, которая выражается в умении подходить к музыкальным произведениям с позиции эстетической меры и улавливать в них эту меру. Живое обсуждение характера исполнения музыкального произведения позволяет актуализировать вопросы интерпретации художественного образа, раскрыть и связать воедино содержание и форму музыкального произведения в поиске меры гармонизации отношений между ними.

Аудитория студии (как правило, молодежь, обучающаяся в музыкальных учебных заведениях) имеет возможность задать гостям вопросы. Музыкальные фрагменты (в живом исполнении или в видеозаписи) усиливают эмоциональное впечатление слушателей и зрителей данной передачи и пробуждают у них интерес к музыке. В рассуждениях о музыке, о ее создателе участники передачи подчеркивают мысль о том, что художественное мышление как единое пространство взаимодействия композитора, исполнителя и слушателя по своей природе символично и метафорично, так как насыщает диалогическими смыслами через подобное духу эстетическое вчувствование - условие единства эстетического и творческого отношений к миру. «Созидая новые миры», искусство оказывается «практикой в духе», что определяет его уникальную роль в системе видов человеческой деятельности и в творимой ею культуре» [Каган, 1997, с. 83].

Успех передачи «Нескучная классика» во многом обусловлен стилистически выверенной и обоснованной музыковедческой позицией ее авторов, позволяющей сочетать точность жанровой и образной характеристики музыки с нахождением разнообразных ракурсов подачи материала в сопровождении оригинальной интерпретации музыкального сочинения. Обе передачи нацелены на повышение уровня культуры молодежной аудитории, в целом нации, возрождение приоритетов духовности, ибо создатели данных передач понимают, что общение с художественным образом, обобщающим многовековой опыт человечества, обладает магической силой просветления души человеческой [Бочкарева, 2008].

Возросшее влияние СМИ в процессе самореализации личности отмечают многие ученые. Т. С. Злотникова выделяет три уровня идентификации и самореализации личности:

- пространство самовосприятия - оценка личностью себя, своих возможностей, сопровождающаяся актуализацией процессов рефлексии;

- пространство опредмечивания мира «свое» пространство, начиная от личностных качеств заканчивая материальными ценностями;

- пространство взаимодействий, определяемое качеством взаимодействия с людьми [Злотникова, 2019, с. 206].

Передачи «Нескучная классика», «Абсолютный слух» на канале «Культура» выстраиваются создателями как пространство диалога, с его субъектной представленностью во времени отношений личностного и всеобщего, определяющих энергетический потенциал «поля притяжения» к духовной сущности через обнаружение себя в Других, а Других - в себе. Именно поэтому музыкальные передачи на телевидении нацелены на преобразовательную деятельность, изменение личности в пространстве художественного образа, насыщенного идеальным светом гармоничного мироустройства. Создатели данных музыкальных передач убеждены, что посредством красоты открывается новая способность человеческого разума, с помощью которого личность выходит за пределы чисто эмпирической индивидуальности и устремляется к универсальному идеалу человечности. Человек становится символом ценности, пересоздавая свою личность, поскольку индивидуальное переживание стремится стать универсальным, ибо красота воплощает эстетическое единство человека и мира [Бочкарева, 2006].

\section{Заключение}

Медиадискурс выстраивается и функционирует на основе совокупности процессов и продуктов речевой деятельности в сфере массовых средств коммуникации, их взаимодействия и обмена, формируя потребность личности к обсуждению наиболее сложных проблем сопровождается акту- 
ализацией чувствительности к контексту современной социокультурной ситуации.

- Формируемый в СМИ медиаобраз реальной действительности возникает на основе коллективно вырабатываемого ценностно-смыслового поля представляемой информации, фиксирующего ценности воспринимающей аудитории в процессе их актуализации.

- Благодаря поступающей информации, расстановке акцентов в массовом сознании формируется не столько образ действительности, сколько желаемый СМИ виртуальный образ, поле ценностной манипуляции общественным сознанием.

- Стихийный отбор образцов и моделей современного медиадискурса происходит с учетом их популярности, глобальная массовая культура не столько подавляет многообразие, сколько стимулирует его и питается им.

- Механизм функционирования ценностного медиапространства организуется значимыми персонами (professional celebrities) на основе понимания ими культурной, политической, общественной ситуации, которое принимается, признается большинством людей, в этом случае индивидуальное видение лидера возводится в ранг духа времени.

- Важное место в медиапространстве занимает современный музыкальный дискурс, который выполняет информационную и оценочную функции, фиксирует использование определенных языковых средств в музыкальной рецензии, обзоре, эссе, очерках, творческих портретах музыкантов, арт-хрониках, репортажах, музыкальных передачах, документальных аудио- и видеофильмах и др.

- Музыкальный дискурс в современном медиапространстве представлен в трех категориях: профессиональной, профанной и смешанной.

- В эпоху медийности, когда Интернет «оттягивает» на себя большую часть времени современного человека, баланс существования музыкальной культуры смещается в сторону все большего заполнения достаточно примитивными «образцами» шоу-индустрии.

- В качестве известных инструментов шокаудержателей аудитории в разнообразных музыкальных клипах как коммерческих продуктах, используются уложенные в красивую обертку сексуальность, насилие и другие табуированные темы.

- Рост фан-культуры, обилие блогеров свидетельствуют о том, что непрофессиональный контент начинает преобладать над профессиональ- ным, вытесняя его из медиапространства, и это явление требует решения новых этикофилософских, образовательных и воспитательных проблем в перспективе развития профессиональных массмедиа, музыки, кино и др.

- Музыкальные передачи, транслируемые каналом «Культура» («Абсолютный слух» (ведущий - Геннадий Янин, «Нескучная классика» (ведущая - Сати Спивакова), восстанавливают общественную значимость искусства и на основе уважительного отношения к творцам и их творчеству, возрождая просветительские принципы отечественной музыкально-критической журналистики, выполняют важную функцию «служения музыке».

- Музыкальная культура играет важную роль в становлении и развитии личности и мыслится как пространство диалога, пространство духовности.

\section{Библиографический список}

1. Арпентьева М. Р. Развитие музыканта как личности и специалиста и подготовка к компьютингу // Художественная и музыкальная культура в образовании: инновационные пути развития: материалы IV межд. науч.-практ. конф., 27-29 марта 2019 г. / под науч. ред. д-ра пед. н. Л. Г. Савенковой, д-ра пед. н. О. В. Бочкаревой, д-ра иск. М. Г. Долгушиной. Ярославль : РИО ЯГПУ, 2019. С. 16-19.

2. Борисова Е. Молодежная музыка и социализирующая функция СМИ // Наука телевидения. 2012. T. 9. C. $110-115$.

3. Бочкарева О. В. Этико-эстетическая направленность художественного диалога в образовании // Искусство и образование. 2006. № 6. С. 49-69.

4. Бочкарева О. В. Культурологические основы художественно-педагогического диалога // Искусство и образование. 2008. № 1(5). С. 4-14.

5. Гольденцвайг Г. Д. Роль фан-аудитории в непрофессиональных медиа в распространении музыки // Вестник Московского университета. Серия 10. Журналистика. 2009. № 6. С. 69-88.

6. Злотникова Т. С. Интеллектуал на отечественном телевидении: массовое и маргинальное / Т. С. Злотникова, И. А. Хрящева // Ярославский педагогический вестник. 2019. № 2 (107). С. 204-209.

7. Зубанова Л. Б. Современное медиапространство: подходы к исследованию и принципы интерпретации // Вестник Челябинской государственной академии культуры и искусств. 2008. № 2(14). С. 6-16.

8. Каган М. С. Эстетика как философская наука. Санкт-Петербург : ТООТК «Петрополис», 1997. 554 с.

9. Кант И. Критика способности суждения // История эстетики: памятники мировой эстетической мысли : в 5-т. / гл. ред. М. Ф. Овсянников. Т. 3. Москва : Изд-во Академии художеств СССР, 1963. 1008 с. 
10. Курышева Т. Музыкальная журналистика и музыкальная критика. Москва : Владос-Пресс, 2007. $295 \mathrm{c}$.

11. Миронов В. В. Современное коммуникативное пространство как фактор трансформации культуры и философии // Вестник Моск. ун-та. Серия 7. Философия. 2006. С. 34-48.

12. Морозова Н. М. Лексикографические и лингвокультурные логические аспекты музыкального дискурса в сети Интернет / Н. М. Морозова, А. А. Чернобров // Вестник Новосиб. гос. пед. ун-та. 2016. № 2(30). C. 138-147.

13. Медушевский В. В. Музыкальное произведение и музыкальный язык // Спутник учителя музыки / сост. Т. В. Челышева. Москва : Просвещение, 1993. C. $116-120$.

14. Птушко Л. А. Музыкальное просветительство в контексте музыковедения // Музыкальная академия. 2009. № 1(4). С. 15-18.

15. Разлогов К.Э. Медиаобразование в социокультурном контексте // Ярославский педагогический вестник. 2019. № 2 (107). С. 144-152.

16. Шапинская Е. Н. Эскапизм в пространстве массовой культуры // Ярославский педагогический вестник. 2019. № 1 (106). С. 180-185.

17. Barnier M. The Sound of the First French Television Adverticements Music Sound and Moving Image. LUP. 2008. V. 2. P. 149

18. Burnett R., Baum N. Amateuz Express: International Fan Labour in Swedish Independent Music Conference Paper. Copenhagen, 2008.

19. Machin D. Analising popular music: Image, sound, text. L.: Sage, 2010. 240 p.

\section{Reference list}

1. Arpent'eva M. R. Razvitie muzykanta kak lichnosti i specialista i podgotovka k komp'jutingu = Development of the musician as a person and specialist and preparation for computing // Hudozhestvennaja i muzykal'naja kul'tura $\mathrm{v}$ obrazovanii: innovacionnye puti razvitija : Art and music culture in education: innovative ways of development : materialy IV mezhd. nauch.-prakt. konf., 27-29 marta 2019 g. / pod nauch. red. d-ra ped. n. L. G. Savenkovoj, d-ra ped. n. O. V. Bochkarevoj, d-ra isk. M. G. Dolgushinoj. Jaroslavl' : RIO JaGPU, 2019. S. 16-19.

2. Borisova E. Molodezhnaja muzyka i socializirujushhaja funkcija SMI = Youth music and the socializing function of the media // Nauka televidenija. 2012. T. 9. S. 110-115.

3. Bochkareva O. V. Jetiko-jesteticheskaja napravlennost' hudozhestvennogo dialoga $\mathrm{v}$ obrazovanii $=$ Ethical and aesthetic orientation of artistic dialogue in education // Iskusstvo i obrazovanie. 2006. № 6. S. 49-69.

4. Bochkareva O. V. Kul'turologicheskie osnovy hudozhestvenno-pedagogicheskogo dialoga $=$ Cultural foundations of artistic and pedagogical dialogue // Iskusstvo i obrazovanie. 2008. № 1(5). S. 4-14.

5. Gol'dencvajg G. D. Rol' fan-auditorii $v$ neprofessional'nyh media $\mathrm{v}$ rasprostranenii muzyki $=$ The role of fan audiences in non-professional media in the distribution of music // Vestnik Moskovskogo universiteta. Serija 10. Zhurnalistika. 2009. № 6. S. 69-88.

6. Zlotnikova T. S. Intellektual na otechestvennom televidenii: massovoe $\mathrm{i}$ marginal'noe $=$ Intellectual on domestic television: mass and marginal / T. S. Zlotnikova, I. A. Hrjashheva // Jaroslavskij pedagogicheskij vestnik. 2019. № 2 (107). S. 204-209.

7. Zubanova L. B. Sovremennoe mediaprostranstvo: podhody $\mathrm{k}$ issledovaniju i principy interpretacii $=$ Modern media space: approaches to research and principles of interpretation // Vestnik Cheljabinskoj gosudarstvennoj akademii kul'tury i iskusstv. 2008. № 2(14). S. 6-16.

8. Kagan M. S. Jestetika kak filosofskaja nauka = Aesthetics as a philosophical science. Sankt-Peterburg: TOOTK «Petropolis», 1997. $554 \mathrm{~s}$.

9. Kant I. Kritika sposobnosti suzhdenija = Criticism of the ability of judgment // Istorija jestetiki: pamjatniki mirovoj jesteticheskoj mysli: v 5-t./ gl. red. M. F. Ovsjannikov. T. 3. Moskva : Izd-vo Akademii hudozhestv SSSR, 1963. $1008 \mathrm{~s}$.

10. Kurysheva T. Muzykal'naja zhurnalistika i muzykal'naja kritika = Music journalism and music criticism. Moskva : Vlados-Press, 2007. 295 s.

11. Mironov V. V. Sovremennoe kommunikativnoe prostranstvo kak faktor transformacii kul'tury i filosofii = Modern communicative space as a factor in the transformation of culture and philosophy // Vestnik Mosk. un-ta. Serija 7. Filosofija. 2006. S. 34-48.

12. Morozova N. M. Leksikograficheskie i lingvokul'turnye logicheskie aspekty muzykal'nogo diskursa $v$ seti internet $=$ Lexicographic and linguisticcultural logical aspects of music discourse on the Internet / N. M. Morozova, A. A. Chernobrov // Vestnik Novosib. gos. ped. un-ta. 2016. № 2(30). S. 138-147.

13. Medushevskij V. V. Muzykal'noe proizvedenie i muzykal'nyj jazyk = Musical work and language // Sputnik uchitelja muzyki / sost. T. V. Chelysheva. Moskva : Prosveshhenie, 1993. S. 116-120.

14. Ptushko L. A. Muzykal'noe prosvetitel'stvo v kontekste muzykovedenija $=$ Musical enlightenment in the context of musicology // Muzykal'naja akademija. 2009. № 1(4). S. 15-18.

15. Razlogov K. Je. Mediaobrazovanie v sociokul'turnom kontekste $=$ Media education in a sociocultural context // Jaroslavskij pedagogicheskij vestnik. 2019. № 2 (107). S. 144-152.

16. Shapinskaja E. N. Jeskapizm $\mathrm{v}$ prostranstve massovoj kul'tury = Escapism in the space of mass culture // Jaroslavskij pedagogicheskij vestnik. 2019. № 1 (106). S. 180-185.

17. Barnier M. The Sound of the First French Television Adverticements Music Sound and Moving Image. LUP. 2008. V. 2. P. 149.

18. Burnett R., Baum N. Amateuz Express: International Fan Labour in Swedish Independent Music Conference Paper. Copenhagen, 2008.

19. Machin D. Analising popular music: Image, sound, text. L.: Sage, 2010. 240 p. 